\title{
Transcription factor-based biosensors in biotechnology: current state and future prospects
}

\author{
Regina Mahr ${ }^{1}$. Julia Frunzke ${ }^{1}$
}

Received: 8 August 2015 /Revised: 8 October 2015 / Accepted: 13 October 2015 /Published online: 31 October 2015

(C) The Author(s) 2015. This article is published with open access at Springerlink.com

\begin{abstract}
Living organisms have evolved a plethora of sensing systems for the intra- and extracellular detection of small molecules, ions or physical parameters. Several recent studies have demonstrated that these principles can be exploited to devise synthetic regulatory circuits for metabolic engineering strategies. In this context, transcription factors (TFs) controlling microbial physiology at the level of transcription play a major role in biosensor design, since they can be implemented in synthetic circuits controlling gene expression in dependency of, for example, small molecule production. Here, we review recent progress on the utilization of TF-based biosensors in microbial biotechnology highlighting different areas of application. Recent advances in metabolic engineering reveal TF-based sensors to be versatile tools for strain and enzyme development using high-throughput (HT) screening strategies and adaptive laboratory evolution, the optimization of heterologous pathways via the implementation of dynamic control circuits and for the monitoring of single-cell productivity in live cell imaging studies. These examples underline the immense potential of TF-based biosensor circuits but also identify limitations and room for further optimization.
\end{abstract}

Keywords Transcriptional regulator · Biosensor · Metabolic engineering $\cdot$ Screening $\cdot$ Evolution $\cdot$ Single-cell analysis

Julia Frunzke

j.frunzke@fz-juelich.de

1 Institute of Bio- and Geosciences, IBG-1: Biotechnology, Forschungszentrum Jülich GmbH, 52425 Jülich, Germany

\section{Introduction}

In the last century, the era of metabolic engineering resulted in an enormous increase in microbial processes for the production of value-added compounds, such as proteins, amino acids, biofuels, organic acids and polymer precursors. Based on renewable feedstocks, the efficient establishment and optimization of bioprocesses is the key to a transition from the currently petroleum-dependent and energy-intensive chemical industry towards a sustainable bioeconomy.

Exploiting microorganisms for large-scale production requires, on the one hand, elaborated high-throughput (HT) tools for strain engineering, and, on the other hand, techniques for analyzing the performance of producer strains and the efficiency of bioprocesses. Recent studies using metabolic flux analysis and in silico modelling approaches enable new insights into the bacterial physiology during fermentation (Wiechert and Noack 2011); however, the formation of inefficient subpopulations affecting the outcome of the bioprocess is often neglected (Delvigne and Goffin 2014; Lieder et al. 2014). While rational strain engineering is limited by the high physiological complexity of microbes, traditional random mutagenesis strategies are restricted by the selection and screening capacity, which requires a readily accessible phenotype linked to product formation (Dietrich et al. 2010; Schallmey et al. 2014). During the past decade, advances in synthetic biology significantly contributed to the establishment of novel metabolic engineering tools (Ng et al. 2015; Wendisch 2014). For example, genetically encoded biosensors have proven to be of high value for various applications in strain engineering, dynamic pathway control and single-cell analysis. The basic principle is based on metabolite-sensing proteins (e.g. transcription factors, enzymes or periplasmic-binding proteins) or RNAs (e.g. riboswitches and ribozymes) which are activated upon binding of effector molecules and control in turn the 
expression of an actuator part (e.g. fluorescent reporters, regulatory switches or selection markers). This biosensor architecture enables the intracellular detection of metabolite production by converting it into a measureable output (Fig. 1).

In the following sections, we will review recent progress regarding the design of biosensor circuits based on transcription factors (TFs) and their application in metabolic engineering strategies including HT screening approaches, dynamic pathway control, biosensor-driven evolution and single-cell analysis (Fig. 2). We will not include the application of TFbased biosensors for the detection of environmental pollutants, which is reviewed elsewhere (Fernandez-Lopez et al. 2015; van der Meer and Belkin 2010). For recent review articles on RNA- and FRET-based biosensors, see Frommer et al. (2009), Liang et al. (2011), Michener et al. (2012), Schallmey et al. (2014) and Zhang et al. (2015).

\section{Exploiting nature's toolbox-transcription factor-based biosensors}

Living organisms have evolved a variety of different sensor principles to monitor the intra- or extracellular accumulation of small molecules, ions or changes in physical parameters. In prokaryotes, TFs play a major role in physiological adaptation by controlling gene expression at the level of transcription- typically by interfering with the binding of the RNA polymerase to DNA. The activity of TFs can be affected by the interaction with small (effector) molecules, ions, physical parameters (e.g. temperature or $\mathrm{pH}$ ), protein-protein interaction or protein modification. In several recent studies, researchers have demonstrated that these mechanisms provide a versatile toolbox for applications in metabolic engineering and singlecell analysis of production strains (Table 1) (Liu et al. 2015a; Michener et al. 2012; Schallmey et al. 2014).

Especially, metabolite-responsive TFs have proven to be valuable tools for biotechnological applications and have been integrated into a diverse set of synthetic regulatory circuits enabling the detection of, for example, amino acids (Binder et al. 2012; Mustafi et al. 2012), succinate (Dietrich et al. 2013), butanol (Dietrich et al. 2013), malonyl-CoA (Xu et al. 2014a, b) and secondary metabolites (Siedler et al. 2014b). These circuits are typically based on a previously well-characterized TF which limits the rapid access to novel metabolite sensors to a small set of known TFs. However, the principle of substrate-induced gene expression (SIGEX), where fragments of a metagenomic library can be ligated into an operon-trap vector in front of a suitable reporter gene (e.g. $g f p$ ), might represent an option to overcome this limitation (Uchiyama and Miyazaki 2010b; Uchiyama and Watanabe 2008). Originally developed for the screening of novel enzymes and biosynthetic operons, this design can in principle also be exploited to screen metagenomic libraries for effector-

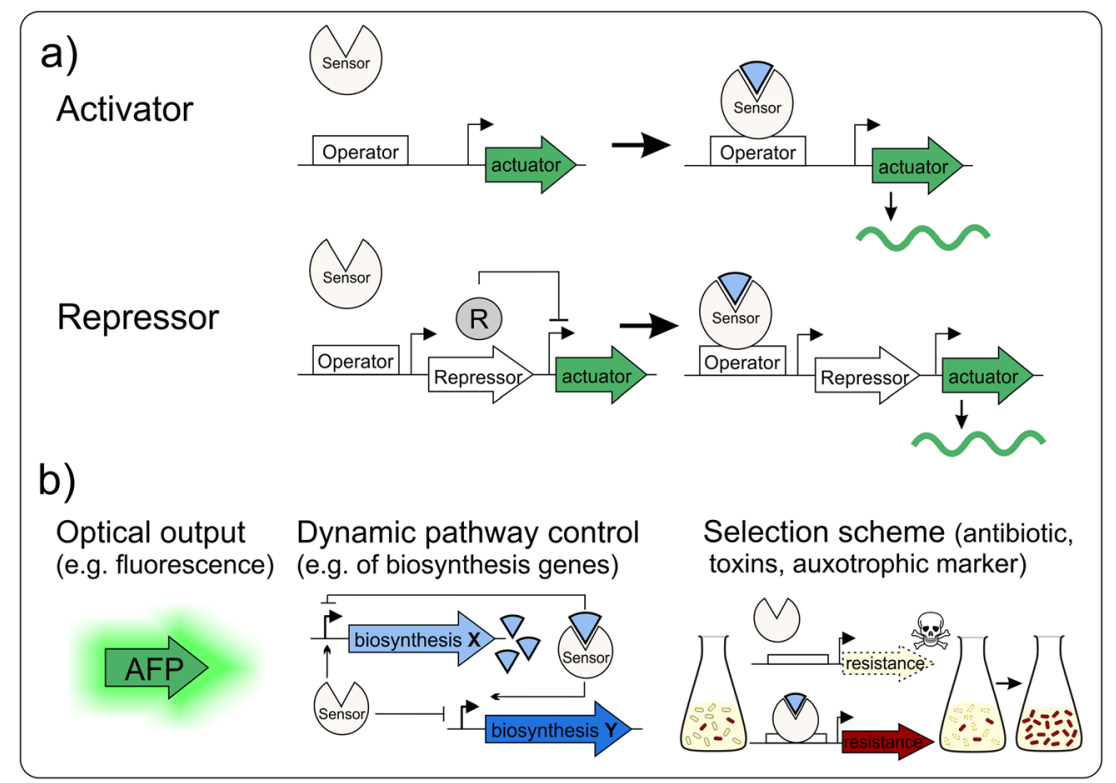

Fig. 1 Principles for the architecture of transcription factor-based biosensors. a A transcriptional activator may be used to activate expression of an actuator gene (circuit) in response to effector molecules. In contrast, repressors block the expression of actuators. By setting the expression of a second repressor under the control of the TFbiosensor repressor, the signalling can be inverted, resulting in a positive output of the actuator module. b Depending on the final function, different actuators are available as biosensor readout. The expression of e.g. autofluorescent proteins (AFP) results in an optical output, while the insertion of the biosensor into regulatory circuits can trigger and dynamically control biosynthetic pathways. Sensors can further be used to generate an artificial selection scheme by the choice of a suitable actuator (e.g. antibiotics, toxins or auxotrophy) controlling the survival of strains with desired traits 


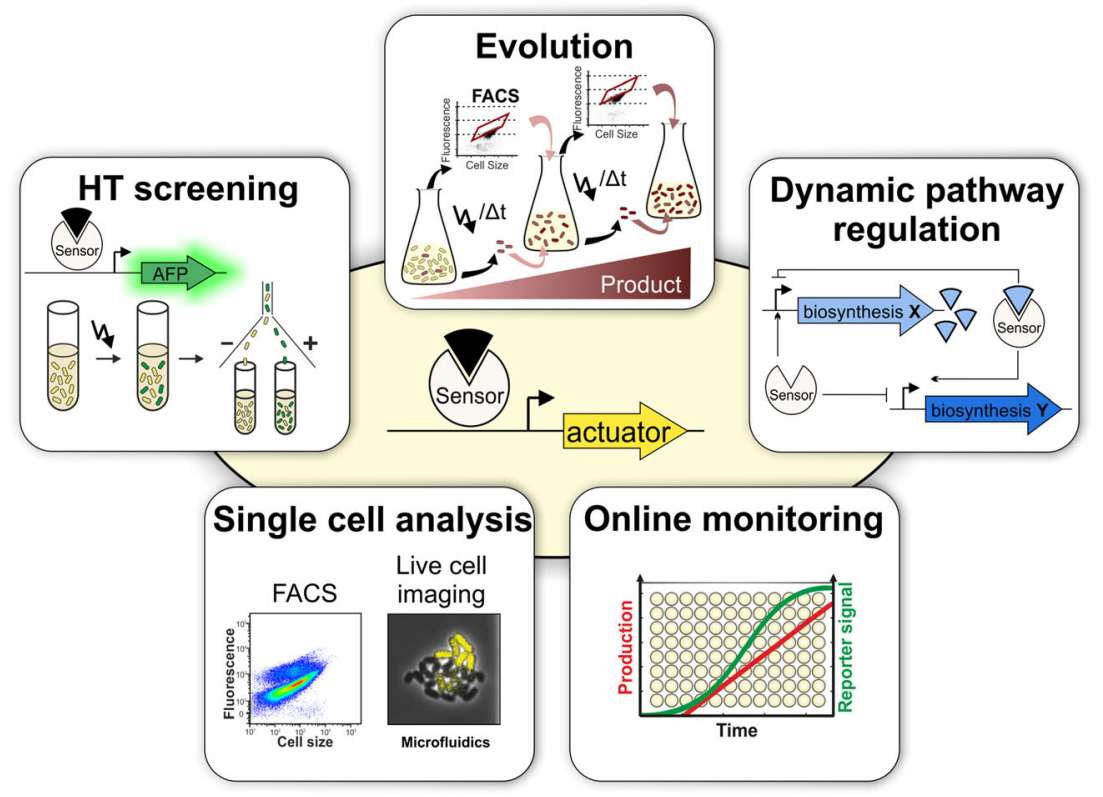

Fig. 2 Versatile applications of TF-based biosensors. Biosensors with an optical readout, e.g. production of an autofluorescent protein $(A F P)$, are efficient tools for the high-throughput (HT) screening of large mutant libraries using fluorescence-activated cell sorting (FACS). Biosensordriven evolution has proven a convenient strategy to increase production by iteratively imposing an artificial selective pressure on the fluorescent output of a biosensor using FACS or selection schemes.

responsive TF-promoter pairs. Furthermore, global databases like DBD (www.transcriptionfactor.org; (Wilson et al. 2008)), RegPrecise (http://regprecise.lbl.gov/RegPrecise; (Novichkov et al. 2013)) or PRODORIC (www.prodoric.de; (Münch et al. 2003)) are useful tools to gain information on prokaryotic transcription factors and regulons. Finally, plenty of species-specific databases are available, including RegulonDB (http://regulondb.ccg.unam.mx; (Salgado et al. 2006)) and EcoCyc (http://ecocyc.org; (Keseler et al. 2013)) for Escherichia coli or CMRegNet (www.lgcm.icb.ufmg.br/ cmregnet; (Abreu et al. 2015)) for corynebacterial and mycobacterial species which also provide valuable information regarding regulatory circuits for the development of novel sensor devices.

Besides classical one-component TFs, the principle of twocomponent signalling (TCS) represents a promising mode for the extracellular detection of small molecules in production strains or synthetic communities. Previous studies have already demonstrated that the modular design of TCS can be exploited to create sensor kinases with novel effector specificities and to transduce the information to the level of gene expression (Ohlendorf et al. 2012). In a recent study, Ganesh and co-workers reported on the construction of a chimeric, malate-responsive TCS by fusing the sensor domain of MalK (Bacillus subtilis) to the kinase domain of EnvZ (Escherichia coli) thereby controlling the activity of the отр $C$ promoter in response to external malate accumulation
Integrated into synthetic regulatory circuits, biosensors can be used for the dynamic control of biosynthetic pathways in order to avoid, for example, the accumulation of toxic intermediates. Finally, biosensors are convenient tools for non-invasive online monitoring of production processes and for analysis at single-cell resolution using FACS and live cell imaging in microfluidic chip devices

(Ganesh et al. 2015). To ensure specific signal transduction and to avoid detrimental cross-talk to host TCSs, the stoichiometry, the expression level of the protein components, as well as the potential phosphatase activity of the sensor kinase remain critical aspects to be considered for the design of TCSbased biosensors (Podgornaia and Laub 2013).

An alternative principle for intra- or extracellular sensing is represented by extracytoplasmic function (ECF) sigma factors (Mascher 2013). The orthogonality of ECF-based switches has recently been demonstrated by a proof-of-principle study describing the construction of a bistable switch in E. coli (Chen and Arkin 2012) and was further developed by Rhodius et al., who characterized ECF sigma factor families in bacteria using bioinformatics. The authors reported on 20 highly orthogonal combinations of sigma factors and their cognate promoters (Rhodius et al. 2013). These studies provide a promising basis for the design of synthetic circuits in metabolic engineering.

\section{High-throughput screening}

Genetically encoded biosensors enable the specific translation of intracellular product accumulation into a screenable (e.g. fluorescence) or selectable (e.g. antibiotic resistance) output by driving the production of a reporter protein (Fig. 1b). Consequently, an important field of biosensor application is 
Table 1 Overview of TF-based biosensors applied in biotechnological strain development and screening approaches

\begin{tabular}{|c|c|c|c|c|}
\hline $\mathrm{TF}$ & Analyte & Host chassis & Output & Application \\
\hline $\begin{array}{l}\text { AraC-Idi } \\
\text { on AraC of } E \text {. coli }\end{array}$ & $\begin{array}{l}\text { Isopentenyl diphosphate } \\
\text { (lycopene) }\end{array}$ & E. coli & MutD5-mCherry & $\begin{array}{l}\text { Improvement of isopentenyl diphosphate } \\
\text { production of } E \text {. coli using a biosensor- } \\
\text { controlled mutator strategy. Visualization of the } \\
\text { production by the biosensor output (Chou and } \\
\text { Keasling 2013) }\end{array}$ \\
\hline BenR of $P$. putida & Benzoate & E. coli & GFP & $\begin{array}{l}\text { Screening of a metagenomics library for improved } \\
\text { amidase activities (Uchiyama and Miyazaki } \\
\text { 2010a) }\end{array}$ \\
\hline $\begin{array}{l}\text { BmoR of Thauera } \\
\text { butanivorans }\end{array}$ & $\begin{array}{l}\text { 1-Butanol (response to linear } \\
\text { and branched-chain alcohols) }\end{array}$ & E. coli & TetA-GFP & $\begin{array}{l}\text { Improvement of 1-butanol production of } E \text {. coli by } \\
\text { a biosensor-based selection scheme. } \\
\text { Simultaneous monitoring of growth and } \\
\text { fluorescence as measure of the biosensor output } \\
\text { (Dietrich et al. 2013) }\end{array}$ \\
\hline CysR of C. glutamicum & O-acetyl (homo-) serine & C.glutamicum & eYFP & $\begin{array}{l}\text { Visualization of sulphur limitation at the single cell } \\
\text { level (Hoffmann et al. 2013) }\end{array}$ \\
\hline DcuR of E. coli & Succinate & E. coli & TetA & $\begin{array}{l}\text { Proof-of-concept study: linking dicarboxylic acid } \\
\text { production to bacterial growth (Dietrich et al. } \\
\text { 2013) }\end{array}$ \\
\hline FadR of E. coli & Fatty acid/acyl-CoA & E. coli & RFP/regulatory circuit & $\begin{array}{l}\text { Implementation of a synthetic circuit for dynamic } \\
\text { pathway control of the production of fatty acid } \\
\text { ethyl ester in } E \text {. coli (Zhang et al. 2012) }\end{array}$ \\
\hline FapR of $B$. subtilis & Malonyl-CoA & E. coli & eGFP/regulatory circuit & $\begin{array}{l}\text { - Design and kinetic analysis of a malonyl-CoA } \\
\text { sensor in E. coli (Xu et al. 2014b) } \\
\text { - TF-based negative feedback loop for the dynamic } \\
\text { control of fatty acid biosynthesis in dependency } \\
\text { of the intracellular malonyl-CoA level (Liu et al. } \\
\text { 2015b) }\end{array}$ \\
\hline LacI of E. coli & IPTG, lactose & E. coli & GFP & $\begin{array}{l}\text { Live cell imaging study of the correlation between } \\
\text { growth rate fluctuations and metabolic } \\
\text { stochasticity (Kiviet et al. 2014) }\end{array}$ \\
\hline Lrp of C. glutamicum & $\begin{array}{l}\text { L-valine } \\
\text { L-leucine } \\
\text { L-isoleucine } \\
\text { L-methionine }\end{array}$ & C.glutamicum & eYFP & $\begin{array}{l}\text { - HT FACS screening of a chemically mutagenized } \\
\text { C. glutamicum wt library (Mustafi et al. 2012) } \\
\text { - Live cell imaging of L-valine production of } \\
\text { PDHC-deficient C. glutamicum strains (Mustafi } \\
\text { et al. 2014) } \\
\text { - Biosensor-driven evolution of L-valine } \\
\text { production (Mahr et al. 2015) }\end{array}$ \\
\hline LysG of $C$. glutamicum & $\begin{array}{l}\text { L-lysine } \\
\text { L-arginine } \\
\text { L-histidine }\end{array}$ & C.glutamicum & eYFP & $\begin{array}{l}\text { - HT FACS screening of a chemically mutagenized } \\
\text { C. glutamicum wt library (Binder et al. 2012) } \\
\text { - Screening of enzyme libraries for feedback- } \\
\text { resistant variants of key enzymes for amino acid } \\
\text { production (Schendzielorz et al. 2014) }\end{array}$ \\
\hline NahR of $P$. putida & Benzoic acids & E. coli & TetA & $\begin{array}{l}\text { Proof-of-concept study: selection of biocatalysts } \\
\text { by the implementation of a TF-based selection } \\
\text { scheme (van Sint Fiet et al. 2006) }\end{array}$ \\
\hline PcaR of $P$. putida & ß-ketoadipate & E. coli & TetA & $\begin{array}{l}\text { Proof-of-concept study: linking } \beta \text {-ketoadipate } \\
\text { production to bacterial growth (Dietrich et al. } \\
\text { 2013) }\end{array}$ \\
\hline SoxR of E. coli & NADPH & E. coli & eYFP & $\begin{array}{l}\text { HT FACS screening of a mutant library of the } \\
\text { NADPH-dependent alcohol dehydrogenase of } \\
\text { Lactobacillus brevis for improved 4-methyl-2- } \\
\text { pentanone (Siedler et al. 2014a) }\end{array}$ \\
\hline TyrR of E. coli & L-tyrosine & E. coli & MutD5-mCherry & $\begin{array}{l}\text { Improvement of L-tyrosine production of } E \text {. coli } \\
\text { using a biosensor-controlled mutator strategy. } \\
\text { Visualization of the production by the biosensor } \\
\text { output (Chou and Keasling 2013) }\end{array}$ \\
\hline
\end{tabular}


implementation in HT screening approaches for the selection of novel or improved biocatalysts (Fig. 2) (Eggeling et al. 2015; Schallmey et al. 2014). Fluorescence-activated cell sorting (FACS) was applied in several recent studies as a particularly suitable HT technique. For example, the transcriptional regulator Lrp of Corynebacterium glutamicum was recently implemented in a FACS HT screening approach for the isolation of mutant strains producing branched-chain amino acids (L-valine, L-leucine and L-isoleucine) from a mutant library after chemical mutagenesis (Mustafi et al. 2012). The native function of Lrp is to sense the intracellular accumulation of branched-chain amino acids and methionine, and in turn to activate the amino acid export system BrnFE in order to avoid high intracellular levels and toxic effects of these amino acids (Lange et al. 2012). These characteristics provide an optimal basis for the construction of biosensors featuring an appropriate dynamic range and sensitivity for the improvement of production strains. In addition, they have a significant advantage in comparison to the use of sensors based on transcriptional (biosynthesis) repressors or periplasmic-binding proteins, which typically display a very high effector affinity. The successful application of a similar activator protein has also been demonstrated by a study using the LysG TF for the isolation of L-lysine-producing strains of C. glutamicum via FACS (Binder et al. 2012).

Furthermore, TF-based sensors were successfully exploited in enzyme screenings. For example, the abovementioned LysG sensor was used to screen enzyme libraries for feedback-resistant enzyme variants for the overproduction of the effector amino acids L-arginine (N-acetyl-L-glutamate kinase), L-histidine (ATP phosphoribosyl transferase) and Llysine (aspartate kinase) (Schendzielorz et al. 2014). An engineered AraC variant was used by Tang and co-workers for the directed evolution of 2-pyrone synthase activity (from Gerbera hybrida) in E. coli. Two iterative rounds of mutagenesis and selection led to the isolation of enzyme variants displaying roughly 20 -fold increased triacetic acid lactone production (Tang et al. 2013). The considerable plasticity of the $\mathrm{AraC}$ protein for the engineering of new effector specificities was already previously demonstrated in a study where a mevalonate-responsive AraC variant was used for the screening of ribosome binding site (RBS) variants in front of a hydroxymethylglutaryl-CoA reductase (Tang and Cirino 2011). A promising alternative to the sensing of product formation was recently demonstrated by the application of an NADPH-responsive biosensor based on E. coli SoxR. This sensor provides a broadly applicable tool for the screening of NADPH-dependent enzymes, as exemplified by screening a dehydrogenase library for enzymes exhibiting improved catalytic activity for the substrate 4-methyl-2-pentanone (Siedler et al. 2014a).

As an alternative to screening strategies, TF-based biosensors can also be integrated in circuits to establish a product- dependent selection scheme driving the expression of, for example, an antibiotic resistance or toxin gene (Fig. 1b) (Dietrich et al. 2013; Raman et al. 2014; van Sint Fiet et al. 2006). The proof-of-principle was provided by a study of van Sint Fiet et al., who used the transcriptional activator NahR which responds to benzoate and 2-hydroxybenzaldehyde by the activation of tetA (or lacZ) expression (van Sint Fiet et al. 2006). The authors suggested that this design enables the efficient selection of novel or improved biocatalysts for chemical synthesis. Suitability of such a circuit design was later, for instance, demonstrated by the improvement of 1-butanol production of engineered $E$. coli by using the putative $\sigma^{54}$-transcriptional activator BmoR and a $\sigma^{54}$-dependent, alcoholregulated promoter $\left(\mathrm{P}_{\mathrm{BMO}}\right)$ from Pseudomonas butanovora driving the expression of a tetA-gfp gene fusion (Dietrich et al. 2013). This setup allowed the simultaneous monitoring of growth and fluorescence as a measure of the biosensor output.

\section{Dynamic pathway control}

In microorganisms, small molecule biosynthesis is typically controlled by a complex regulatory network which optimizes metabolic flux according to the requirements of the host and counteracts the accumulation of toxic intermediates. Consequently, the simple integration of heterologous biosynthetic pathways or enzymes may lead to unbalanced flux and detrimental interference with the host metabolism. In this context, TF-based biosensors can be used to construct synthetic regulatory switches to dynamically regulate metabolic fluxes (Figs. 1b and 2). This has, for example, been achieved by using the fatty acyl-CoA biosensor FadR to coordinate the biosynthesis of acyl-CoA and ethanol as well as the expression of a wax-ester synthase in an $E$. coli strain producing fatty acid ethyl ester (FAEE) (Zhang et al. 2012). Upon accumulation of acyl-CoA, the repressor FadR dissociates from its target promoters, leading to the activation of ethanol biosynthesis and the expression of wax-ester synthase, which converts ethanol and acyl-CoA to FAEE. Similarly, Xu and co-workers designed a hybrid promoter-regulator system based on the malonyl-CoA-responsive TF FapR in E. coli (Xu et al. $2014 b$ ). This regulator was further used to devise different negative feedback loops for the dynamic control of the enzymes acetyl-CoA carboxylase and fatty acid synthase for improved fatty acid biosynthesis as a function of intracellular malonyl-CoA levels (Liu et al. 2015b; Xu et al. 2014a).

The fact that accumulation of toxic intermediates may lead to a complex cellular stress response can also be exploited for the design of synthetic circuits balancing the pathway flux. In contrast to the choice of a well-known TF for circuit design, transcriptome analysis by DNA microarrays or RNA-Seq may be applied to uncover genes whose expression is altered upon 
accumulation of a certain pathway intermediate. For instance, exploiting the cellular response of $E$. coli to the accumulation of farnesyl pyrophosphate was used to balance terpenoid production (Dahl et al. 2013). However, transcriptome analysis provides a snapshot view of the cellular response to metabolite accumulation and, thus, the dynamic behaviour of the particular transcriptional response can hardly be estimated. Furthermore, complex regulatory hierarchies will likely hinder the exact description of the sensor transfer curve and its application for the dynamic control of heterologous pathways.

\section{Biosensor-driven adaptive evolution}

Due to the high physiological complexity of living organisms and the limited knowledge of their underlying mechanisms, alternative approaches are in demand to efficiently engineer bacterial strains for biotechnological applications. Random mutagenesis strategies, however, lead to several hundred undirected small nucleotide polymorphisms (SNPs) genomewide (Harper and Lee 2012), which makes it difficult to identify mutations contributing to the desired phenotypic trait. Evolution approaches driven by mutation and selection have proven a valuable tool to adapt microorganisms to stress conditions (Lee et al. 2013; Oide et al. 2015) or to improve product formation (Reyes et al. 2014; Xie et al. 2015). In several recent strategies, biosensors were successfully implemented to expand adaptive laboratory evolution to include production phenotypes which are not naturally linked to bacterial growth or fitness (Fig. 2) (Chou and Keasling 2013; Dietrich et al. 2013; Mahr et al. 2015; Yang et al. 2013).

Using feedback-regulated evolution of phenotype (FREP), Chou and Keasling dynamically regulated the mutation rate of a strain defective in the DNA repair machinery by controlling the mutator gene (mutD5) as the actuator of a small molecule biosensor (Chou and Keasling 2013). The FREP strategy was successfully applied in E. coli to increase tyrosine production up to fivefold. Using the same strategy, the propagation of high lycopene producer cells for a total cultivation of $432 \mathrm{~h}$ yielded up to $6800 \mu \mathrm{g}$ lycopene $\mathrm{g}^{-1}$ dry cell weight. The application of FREP, however, resulted in several hundred SNPs throughout the entire genome (Chou and Keasling 2013). To reduce the number of mutations, we recently established a biosensor-driven adaptive evolution strategy, which is based on the natural mutation frequency of $10^{-10}$ to $10^{-9}$ mutations per base pair per replication cycle (Mahr et al. 2015). Using FACS, cells exhibiting a high biosensor output (eYFP fluorescence) were iteratively isolated and recultivated. Within five rounds of evolution, growth and the L-valine product formation of a pyruvate-dehydrogenase-deficient C. glutamicum strain were significantly improved, while at the same time a three- to fourfold reduction in by-product (L-alanine) formation was achieved. Four out of seven identified SNPs were reintroduced into the parental strain and were found to significantly increase L-valine production or to reduce by-product formation (Mahr et al. 2015).

Since artificial selection schemes may result in the enrichment of (false positive) cheaters, Raman et al. devised a combination of a positive and negative selection strategy based on the TolC selector (positive selection: sodium dodecylsulphate; negative selection: using colicin E1, (DeVito 2008)). This elegant design enabled the performance of multiple toggled rounds of selection to improve the production of naringenin and glucaric acid (Raman et al. 2014). Altogether, these examples demonstrate that biosensor-driven evolution represents a suitable strategy to complement rational approaches for the engineering of production strains.

\section{Single-cell analysis}

Microbial metabolism is typically analyzed using bulk techniques neglecting single-cell behaviour and the formation of complex phenotypic patterns (Huang 2009; Vasdekis and Stephanopoulos 2015). However, even clonal groups of microorganisms may display significant phenotypic variation which can significantly contribute to the fitness of the whole population in its natural ecological niche (Ackermann 2015). Cell-to-cell variability caused by intrinsic or extrinsic factors may, however, strongly influence bioprocess performance and stability (Delvigne et al. 2014; Müller et al. 2010). The formation of inefficient subpopulations has, for example, been observed in the production of solvent by endospore-forming Clostridia (Tracy et al. 2008), the production of lactobionic acid in Pseudomonas taetrolens (Alonso et al. 2012) and the production of heterologous proteins by $E$. coli (Want et al. 2009), Bacillus megaterium (Münch et al. 2015) and yeast (Carlquist et al. 2012; Newman et al. 2006). However, only a limited number of studies implemented TF-based biosensors for single-cell analysis of production strains, so far (Delvigne et al. 2009; Hoffmann et al. 2013; Mustafi et al. 2014).

Recent advances in live cell imaging approaches using microfluidic chip devices and flow cytometry (FC) have significantly contributed to the analysis and monitoring of microbial populations at single-cell resolution (Fig. 2) (Delvigne and Goffin 2014; Grünberger et al. 2014; Vasdekis and Stephanopoulos 2015). To address the variety of biological questions, different microfluidic chips have recently been developed for the spatiotemporal analysis of microbial populations, including two-dimensional picolitre bioreactor chambers (Grünberger et al. 2012, 2014) as well as onedimensional designs (e.g. the mother machine (Long et al. 2013; Wang et al. 2010)) for the long-term study of bacterial growth and fluorescence. The mother machine structure was, for instance, applied to analyze the correlation of growth rate fluctuations and metabolic stochasticity using a LacI-sensor 
(Kiviet et al. 2014). In this study, Kiviet and co-workers demonstrated how gene expression noise can affect growth rate fluctuations and vice versa, leading to cellular heterogeneity (Kiviet et al. 2014). Recently, the abovementioned Lrp biosensor was applied to monitor L-valine production of pyruvate-dehydrogenase-deficient $C$. glutamicum strains grown in 2D microfluidic chip devices (Mustafi et al. 2014). Interestingly, the addition of small amounts of complex medium compounds, as often used during production processes, resulted in phenotypic heterogeneity during the production phase (Mustafi et al. 2014).

Complementing live cell imaging studies, FC allows the convenient analysis of populations grown in large volumes such as shake flasks or bioreactors by HT processes (Huang 2009; Vasdekis and Stephanopoulos 2015). Combined with biosensors, FC has the potential to identify the formation of subpopulations with respect to metabolic activity, co-factor supply or cell cycle state and to use this information for the optimization of bioprocesses. For example, Delvigne and coworkers revealed subpopulations differing in rpoS expression applying oscillating feed control during fermentation using a transcriptional rpoS-gfpmut2 sensor construct (Delvigne et al. 2009). Furthermore, recent advances in the establishment of downstream analytical methods bring the analysis of isolated subpopulations within reach. Jehmlich and co-workers established a workflow to analyze the proteome of FACSisolated subpopulations by mass spectrometry (Jahn et al. 2013; Jehmlich et al. 2010). This protocol was successfully applied to analyze subpopulations occurring during the growth of Pseudomonas putida KT2440 in bioprocesses (Lieder et al. 2014). Altogether, these examples highlight the recent advances in single-cell analysis of microbial production strains. Combined with TF-based biosensors, these technological advances will significantly increase the resolution of bioprocess monitoring.

\section{Biosensor engineering}

Although nature has evolved a variety of TF-promoter pairs, these sensor devices only exist for a limited number of cellular metabolites (Mustafi et al. 2015; Tang and Cirino 2011). As organisms tightly regulate their transcriptional machinery, endogenous promoter activity and its control are adapted to the organism's purposes. For this reason, biosensors based on native transcription factors and promoters are often limited in sensitivity as well as the dynamic range, and are incompatible with non-native hosts (Blazeck and Alper 2013; Umeyama et al. 2013; Zhang et al. 2012, 2015). Furthermore, many biotechnological applications require the extension of promiscuous transcriptional regulators for specific or non-natural ligands (Looger et al. 2003; Schallmey et al. 2014). Due to the modular architecture of promoter regions
(Blazeck and Alper 2013) and TFs (Galvao et al. 2007), engineering of biosensors for suitable performance characteristics becomes feasible (Fig. 3, Table 2). For example, Zhang and co-workers increased the dynamic range of a sensor system based on the fatty acid-sensing transcriptional regulator FadR about 1000-fold by the introduction of two copies of the FadR-DNA binding sequence into the strong phage lambda $\left(\mathrm{P}_{\mathrm{L}}\right)$ and phage $\mathrm{T7}$ promoters $\left(\mathrm{P}_{\mathrm{A} 1}\right)$ (Lutz and Bujard 1997; Zhang et al. 2012). By combining the FadR binding sites with a LacI operator site in the synthetic promoter, a tight regulation and induction by IPTG and fatty acids was accomplished, yielding a dynamic sensor-regulator system which enabled fatty acid ethyl ester production to be increased threefold (Fig. 3a) (Zhang et al. 2012).

The modulation of the affinity and amount of TF binding sites can likewise contribute to the development of altered effector specificities and sensitivities (de Las Heras et al. 2012; Silva-Rocha and de Lorenzo 2012). For example, the TF BenR (AraC/XylS family) of $P$. putida KT2440 regulates $\mathrm{P}_{\mathrm{b}}$ promoter activity by binding to the $O m-p$ operator site in response to benzoate and with less efficiency to 3methylbenzoate $(3 \mathrm{MBz})$ (Silva-Rocha and de Lorenzo 2012). Interestingly, the completion of a second truncated operator motif upstream of the $O m-p$ site enhanced sensitivity of the sensor construct to $3 \mathrm{MBz}$ four- to fivefold (Fig. 3b) (Bintu et al. 2005a, b; Silva-Rocha and de Lorenzo 2012).

The modular architecture of regulators responding to effector molecules theoretically allows the development of any specificity and sensitivity (Fig. 3c) (Galvao and de Lorenzo 2006). Techniques generating genetic diversity, such as errorprone PCR (Wise and Kuske 2000), chemical and saturation mutagenesis (Tang and Cirino 2011; Tang et al. 2008, 2013) or computational modelling based on crystal structure data sets (Looger et al. 2003; Mandell and Kortemme 2009) contributed to the development of effector-molecule binding sites with altered or novel specificities (Galvao and de Lorenzo 2006). For example, the L-arabinose-response transcriptional regulator $\mathrm{AraC}$ was engineered by saturation mutagenesis to specifically respond to D-arabinose (Tang et al. 2008), to mevalonate (Tang and Cirino 2011) and to triacetic acid lactone (Tang et al. 2013). The de novo design of TF exhibiting the desired effector specificity was, furthermore, reported in a study by Chou and Keasling, who assembled the ligand binding domain of enzymes with the AraC DNA binding domains, yielding a synthetic transcription factor for the sensing of isopentenyl diphosphate (Chou and Keasling 2013). However, complex conformational changes occurring upon ligand binding and inter-domain interactions required for signal transduction make it more difficult to apply this strategy as a ubiquitous design approach.

The orthogonality of functional biological parts (e.g. promoters, coding sequences or terminators) still represents a major objective in the field of synthetic biology 


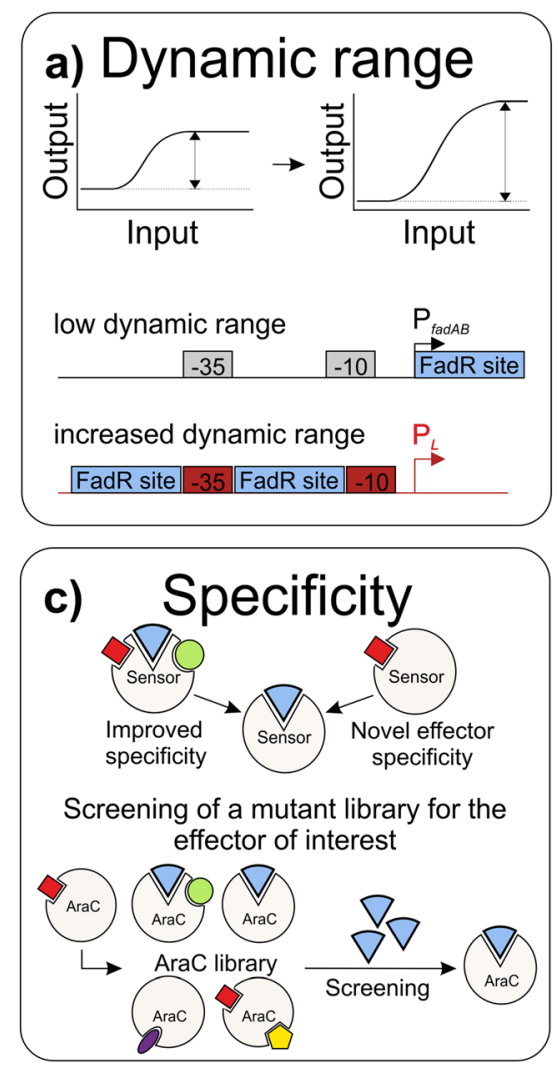

Fig. 3 Examples of biosensor engineering for altered performance characteristics or orthogonal applications. a The dynamic range, describing the maximum fold change of a reporter output to a given input signal (Mustafi et al. 2015), was increased by introducing two FadR binding sites from the $f a d A B$ promoter into the strong lambda phage promoter $\mathrm{P}_{\mathrm{L}}$ (Zhang et al. 2012). b To increase the sensitivity as rate of increase in reporter output (depicted by the slope of the transfer curve) to 3-methylbenzoate $(3 \mathrm{MBz})$, the truncated operator site $O m p-d$ upstream of the operator site $O m p-p$ in the $\mathrm{P}_{b}$ promoter was completed

(Fig. 3d). Libraries of standardized modules (also designated as BioBricks) may contribute to facilitate the engineering of sensor devices. The functional transfer between organisms, however, still remains challenging. In an interesting study, Umeyama and co-workers fused the transcriptional regulator MetJ of $E$. coli to the transcriptional activation domain B42, yielding the synthetic TF MetJB42 which allows S-adenosylmethionine (SAM) sensing in the yeast Saccharomyces cerevisiae (Umeyama et al. 2013). Due to the extremely low diversity of regulatory proteins in mammalian cells, Stanton and co-workers supplied the PhlF repressor of $E$. coli with eukaryotic-specific signals (including a nuclear localization signal) and equipped regulated promoters with multiple operator sites resulting in 2,4-diacetylphloroglucinol recognition in HEK293 cells (Stanton et al. 2014). Although orthogonality still remains problematic, these examples show, however, that the transfer of sensor elements is feasible even across kingdom borders.
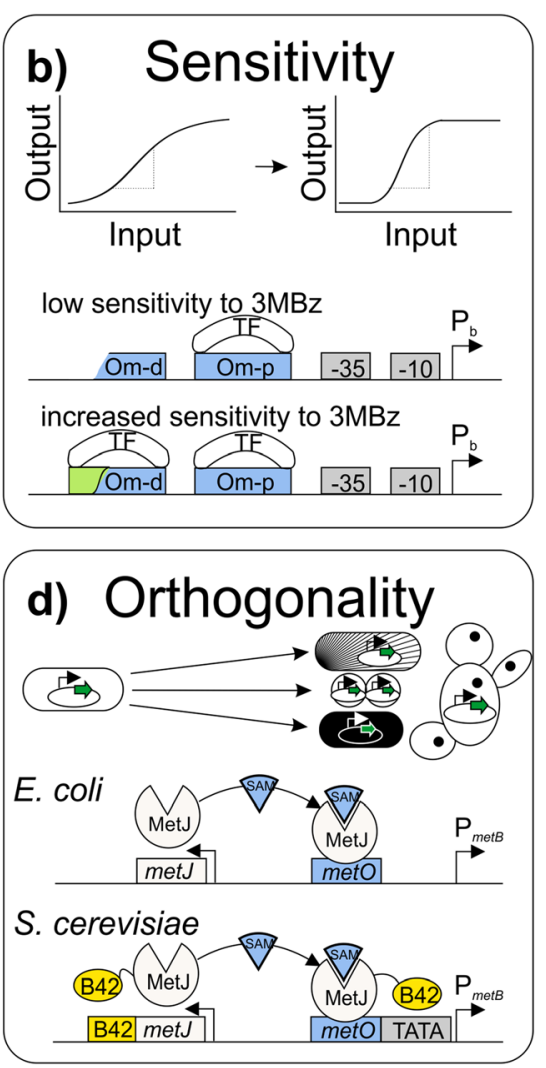

enabling the binding of two benzoate-binding transcription factors (TF) (Silva-Rocha and de Lorenzo 2012). c Furthermore, screening of an AraC mutein library for effectors of interest resulted in the identification of transcription factors with altered specificities (Tang and Cirino 2011; Tang et al. 2013). d The orthogonal transfer of biosensors to host organisms is challenging. Umeyama and co-workers equipped the Sadenosylmethionine $(S A M)$-responsive transcription factor MetJ of E. coli with the transcriptional activator domain B42 resulting in SAM detection in S. cerevisiae (Umeyama et al. 2013)

\section{Future prospects}

TF-based biosensors have significantly contributed to a number of recent metabolic engineering approaches by improving production strains or by identifying non-producing subpopulations during bioprocesses (Fig. 2). However, a detailed molecular understanding of the observed phenotypic patterns during fermentation requires the establishment of highly sensitive Omics techniques interfacing with live cell imaging (e.g. in microfluidic chips) and cytometry analysis and cell sorting. Here, the combination of biosensors with next generation sequencing (e.g. RNA-seq) or high-resolution proteomics appears promising to reveal new insights into subpopulations and may support the identification of bottlenecks during bioprocesses.

Most biosensors reported to date are based on a small number of well-characterized TFs (Table 1). At this point, the screening of promoter libraries or transcriptome analysis using RNA-seq might contribute to harness still uncharacterized 
Table 2 Examples for biosensor engineering

\begin{tabular}{|c|c|c|c|c|}
\hline TF; source & Analyte & Host & Output & Characteristics/architecture \\
\hline AraC-Idiisynth $_{\text {S. coli }}$ & $\begin{array}{l}\text { Isopentenyl diphosphate } \\
\text { (lycopene) }\end{array}$ & E. coli & MutD5-mCherry & $\begin{array}{l}\text { Sensor based on a synthetic TF composed of a } \\
\text { isoprenoid binding domain and the DNA } \\
\text { binding domain of AraC (Chou and Keasling } \\
\text { 2013) }\end{array}$ \\
\hline AraC-mev; E. coli & Mevalonate & E. coli & GFPuv & $\begin{array}{l}\text { Screening of an AraC mutant library for a } \mathrm{TF} \\
\text { with a specific response towards mevalonate } \\
\text { (mutated ligand binding site) (Tang and } \\
\text { Cirino 2011) }\end{array}$ \\
\hline AraC-Mut; E. coli & D-arabinose & E. coli & GFP & $\begin{array}{l}\text { Screening of an AraC mutant library for a TF } \\
\text { with a specific response towards D-arabinose } \\
\text { (mutated ligand binding site) (Tang et al. } \\
\text { 2008) }\end{array}$ \\
\hline AraC-TAL; E. coli & Triacetic acid lactone & E. coli & GFP, LacZ & $\begin{array}{l}\text { Screening of an AraC mutant library for a } \mathrm{TF} \\
\text { with a specific response towards triacetic acid } \\
\text { lactone (mutated ligand binding site) (Tang } \\
\text { et al. 2013) }\end{array}$ \\
\hline BenR; P. putida & Benzoate, 3-methylbenzoate & P. putida & LuxCDABE & $\begin{array}{l}\text { Introduction of a second operator motif into the } \\
\text { promoter region increased specificity of the } \\
\text { biosensor towards 3-methylbenzoate (Silva- } \\
\text { Rocha and de Lorenzo 2012) }\end{array}$ \\
\hline $\begin{array}{l}\text { DcuS/EnvZ chimeric } \\
\text { TCS; } E \text {. coli }\end{array}$ & Fumarate & E. coli & GFP & $\begin{array}{l}\text { Chimeric TCS-based sensor for the extracellular } \\
\text { sensing of fumarate (Ganesh et al. 2013) }\end{array}$ \\
\hline $\begin{array}{l}\text { GAL4-Idi }_{\text {Synth }} ; S . \\
\text { cerevisiae/E. coli }\end{array}$ & $\begin{array}{l}\text { Isopentenyl diphosphate } \\
\text { (isoprenoids) }\end{array}$ & E. coli & Citrine & $\begin{array}{l}\text { Sensor based on a synthetic TF composed of a } \\
\text { isoprenoid binding domain and the DNA } \\
\text { binding domain of GAL4 (Chou and } \\
\text { Keasling 2013) }\end{array}$ \\
\hline $\begin{array}{l}\text { MalK/EnvZ chimeric TCS; } \\
\quad \text { B. subtilis/E. coli }\end{array}$ & Malate & E. coli & GFP & $\begin{array}{l}\text { Sensor based on a chimeric TCS enabling the } \\
\text { extracellular detection of malate by E. coli } \\
\text { (Ganesh et al. 2015) }\end{array}$ \\
\hline MetJ-B42; E. coli & S-adenosyl-methionine & S. cerevisiae & Venus, HIS3 & $\begin{array}{l}\text { Equipment of the E. coli TF MetJ with the } \\
\text { transcriptional activation domain B42 results } \\
\text { in the functional expression in S. cerevisiae } \\
\text { (Umeyama et al. 2013) }\end{array}$ \\
\hline PhlF; E. coli & 2,4-Diacetylphloroglucinol & HEK293 cells & YFP & $\begin{array}{l}\text { Equipment of the } E \text {. coli } \mathrm{TF} \text { PhlF with } \\
\text { eukaryotic-specific signals results in 2,4- } \\
\text { diacetylphloroglucinol recognition in } \\
\text { eukaryotic HEK293 cells (Stanton et al. } \\
\text { 2014) }\end{array}$ \\
\hline XylR; P. putida & $\begin{array}{l}\text { 3-Methyl-benzylalcohol } \\
\text { m-xylene }\end{array}$ & P. putida & LuxCDABE & $\begin{array}{l}\text { Equipment of the biosensor with a positive } \\
\text { feedback loop and an attenuation mechanism } \\
\text { shifted the specificity towards m-xylene (de } \\
\text { Las Heras et al. 2012) }\end{array}$ \\
\hline
\end{tabular}

TFs for biosensor designs. However, accessibility to novel biosensor circuits and sensor components with altered effector specificities (e.g. to non-natural compounds) is key to a broad application in a wide variety of studies. As demonstrated by a number of studies, the modular design of TFs and their respective target promoters make a rapid design of novel circuits feasible (Fig. 3, Table 2). Despite this modularity and in-depth knowledge of the molecular basis, however, the design of synthetic regulatory circuits is not yet like a Lego set. To this end, future attempts must focus on the precise definition of highly orthogonal parts for sensor design and on the efficient generation of custom-made sensor domains with novel specificities and suitable characteristics (sensor transfer curves). Here, the combination of rational design and HT screening of mutant TF libraries appears most promising for efficient sensor design. Furthermore, the integration of synthetic biosensor circuits involves a metabolic burden for the host system which may affect productivity. Especially in the case of integral dynamic control circuits, the expression level of sensor components should be optimized to a minimum level, ensuring sensor functionality but minimizing interference with the host system. 
TF-based biosensors have the potential to revolutionize recent strategies in biotechnological strain development. However, several studies still remain at the level of sensor construction and proof-of-principle applications. To enhance the availability of sensors with appropriate characteristics, more studies are required to establish efficient workflows for biosensor design. Altogether, these efforts should aim to enable an application-oriented construction of biosensors to allow the rapid engineering of required circuits meeting the needs of the particular metabolic engineering purpose.

\section{Compliance with ethical standards}

Funding This work was supported by the German Federal Ministry of Education and Research (BMBF OptoSys grant 031A167B) and the Helmholtz Association (Helmholtz YIG VH-NG-716).

Conflict of interest The authors declare that they have no competing interests.

Ethical approval This article does not contain any studies with human participants or animals performed by any of the authors.

Open Access This article is distributed under the terms of the Creative Commons Attribution 4.0 International License (http:// creativecommons.org/licenses/by/4.0/), which permits unrestricted use, distribution, and reproduction in any medium, provided you give appropriate credit to the original author(s) and the source, provide a link to the Creative Commons license, and indicate if changes were made.

\section{References}

Abreu VA, Almeida S, Tiwari S, Hassan SS, Mariano D, Silva A, Baumbach J, Azevedo V, Rottger R (2015) CMRegNet-An interspecies reference database for corynebacterial and mycobacterial regulatory networks. BMC Genomics 16:452. doi:10.1186/s12864-0151631-0

Ackermann M (2015) A functional perspective on phenotypic heterogeneity in microorganisms. Nat Rev Microbiol 13(8):497-508. doi:10. 1038/nrmicro3491

Alonso S, Rendueles M, Diaz M (2012) Physiological heterogeneity of Pseudomonas taetrolens during lactobionic acid production. Appl Microbiol Biotechnol 96(6):1465-1477. doi:10.1007/s00253-0124254-2

Binder S, Schendzielorz G, Stäbler N, Krumbach K, Hoffmann K, Bott M, Eggeling L (2012) A high-throughput approach to identify genomic variants of bacterial metabolite producers at the single-cell level. Genome Biol 13(5):R40. doi:10.1186/gb-2012-13-5-r40

Bintu L, Buchler NE, Garcia HG, Gerland U, Hwa T, Kondev J, Kuhlman T, Phillips R (2005a) Transcriptional regulation by the numbers: applications. Curr Opin Genet Dev 15(2):125-135. doi:10.1016/j. gde.2005.02.006

Bintu L, Buchler NE, Garcia HG, Gerland U, Hwa T, Kondev J, Phillips R (2005b) Transcriptional regulation by the numbers: models. Curr Opin Genet Dev 15(2):116-124. doi:10.1016/j.gde.2005.02.007

Blazeck J, Alper HS (2013) Promoter engineering: recent advances in controlling transcription at the most fundamental level. Biotechnol J 8(1):46-58. doi:10.1002/biot.201200120
Carlquist M, Fernandes RL, Helmark S, Heins AL, Lundin L, Sorensen SJ, Gernaey KV, Lantz AE (2012) Physiological heterogeneities in microbial populations and implications for physical stress tolerance. Microb Cell Factories 11:94. doi:10.1186/1475-2859-11-94

Chen D, Arkin AP (2012) Sequestration-based bistability enables tuning of the switching boundaries and design of a latch. Mol Syst Biol 8: 620. doi:10.1038/msb.2012.52

Chou HH, Keasling JD (2013) Programming adaptive control to evolve increased metabolite production. Nat Commun 4:2595. doi:10. 1038/ncomms3595

Dahl RH, Zhang F, Alonso-Gutierrez J, Baidoo E, Batth TS, ReddingJohanson AM, Petzold CJ, Mukhopadhyay A, Lee TS, Adams PD, Keasling JD (2013) Engineering dynamic pathway regulation using stress-response promoters. Nat Biotechnol 31(11):1039-1046. doi: $10.1038 / \mathrm{nbt} .2689$

de Las Heras A, Fraile S, de Lorenzo V (2012) Increasing signal specificity of the TOL network of Pseudomonas putida mt-2 by rewiring the connectivity of the master regulator XylR. PLoS Genet 8(10): e1002963. doi:10.1371/journal.pgen.1002963

Delvigne F, Goffin P (2014) Microbial heterogeneity affects bioprocess robustness: dynamic single-cell analysis contributes to understanding of microbial populations. Biotechnol J 9(1):61-72. doi:10.1002/ biot.201300119

Delvigne F, Boxus M, Ingels S, Thonart P (2009) Bioreactor mixing efficiency modulates the activity of a PrpoS::GFP reporter gene in E. coli. Microb Cell Factories 8:15. doi:10.1186/1475-2859-8-15

Delvigne F, Zune Q, Lara AR, Al-Soud W, Sorensen SJ (2014) Metabolic variability in bioprocessing: implications of microbial phenotypic heterogeneity. Trends Biotechnol 32(12):608-616. doi:10.1016/j. tibtech.2014.10.002

DeVito JA (2008) Recombineering with tolC as a selectable/ counter-selectable marker: remodeling the rRNA operons of Escherichia coli. Nucleic Acids Res 36(1):e4. doi:10.1093/ nar/gkm1084

Dietrich JA, McKee AE, Keasling JD (2010) High-throughput metabolic engineering: advances in small-molecule screening and selection. Annu Rev Biochem 79:563-590. doi:10.1146/annurev-biochem062608-095938

Dietrich JA, Shis DL, Alikhani A, Keasling JD (2013) Transcription factor-based screens and synthetic selections for microbial smallmolecule biosynthesis. ACS Synth Biol 2(1):47-58. doi:10.1021/ sb300091d

Eggeling L, Bott M, Marienhagen J (2015) Novel screening methodsbiosensors. Curr Opin Biotechnol 35C:30-36. doi:10.1016/j.copbio. 2014.12.021

Fernandez-Lopez R, Ruiz R, de la Cruz F, Moncalian G (2015) Transcription factor-based biosensors enlightened by the analyte. Front Microbiol 6:648. doi:10.3389/fmicb.2015.00648

Frommer WB, Davidson MW, Campbell RE (2009) Genetically-encoded biosensors based on engineered fluorescent proteins. Chem Soc Rev 38(10):2833-2841. doi:10.1039/b907749a

Galvao TC, de Lorenzo V (2006) Transcriptional regulators à la carte: engineering new effector specificities in bacterial regulatory proteins. Curr Opin Biotechnol 17(1):34-42. doi:10.1016/j.copbio. 2005.12.002

Galvao TC, Mencia M, de Lorenzo V (2007) Emergence of novel functions in transcriptional regulators by regression to stem protein types. Mol Microbiol 65(4):907-919. doi:10.1111/j.1365-2958. 2007.05832.x

Ganesh I, Ravikumar S, Lee SH, Park SJ, Hong SH (2013) Engineered fumarate sensing Escherichia coli based on novel chimeric twocomponent system. J Biotechnol 168(4):560-566. doi:10.1016/j. jbiotec.2013.09.003

Ganesh I, Ravikumar S, Yoo IK, Hong SH (2015) Construction of malate-sensing Escherichia coli by introduction of a novel chimeric 
two-component system. Bioprocess Biosyst Eng 38(4):797-804. doi:10.1007/s00449-014-1321-3

Grünberger A, Paczia N, Probst C, Schendzielorz G, Eggeling L, Noack S, Wiechert W, Kohlheyer D (2012) A disposable picolitre bioreactor for cultivation and investigation of industrially relevant bacteria on the single cell level. Lab Chip 12(11):2060-2068. doi:10.1039/c2lc40156h

Grünberger A, Wiechert W, Kohlheyer D (2014) Single-cell microfluidics: opportunity for bioprocess development. Curr Opin Biotechnol 29:15-23. doi:10.1016/j.copbio.2014.02.008

Harper M, Lee CJ (2012) Genome-wide analysis of mutagenesis bias and context sensitivity of N-methyl-N'-nitro-N-nitrosoguanidine (NTG). Mutat Res 731(1-2):64-67. doi:10.1016/j.mrfmmm.2011.10.011

Hoffmann K, Grünberger A, Lausberg F, Bott M, Eggeling L (2013) Visualization of imbalances in sulfur assimilation and synthesis of sulfur-containing amino acids at the single-cell level. Appl Environ Microbiol 79(21):6730-6736. doi:10.1128/AEM.01804-13

Huang S (2009) Non-genetic heterogeneity of cells in development: more than just noise. Development 136(23):3853-3862. doi:10.1242/dev. 035139

Jahn M, Seifert J, von Bergen M, Schmid A, Buhler B, Müller S (2013) Subpopulation-proteomics in prokaryotic populations. Curr Opin Biotechnol 24(1):79-87. doi:10.1016/j.copbio.2012.10.017

Jehmlich N, Hübschmann T, Gesell Salazar M, Volker U, Benndorf D, Müller S, von Bergen M, Schmidt F (2010) Advanced tool for characterization of microbial cultures by combining cytomics and proteomics. Appl Microbiol Biotechnol 88(2):575-584. doi:10.1007/ s00253-010-2753-6

Keseler IM, Mackie A, Peralta-Gil M, Santos-Zavaleta A, Gama-Castro S, Bonavides-Martinez C, Fulcher C, Huerta AM, Kothari A, Krummenacker M, Latendresse M, Muniz-Rascado L, Ong Q, Paley S, Schroder I, Shearer AG, Subhraveti P, Travers M, Weerasinghe D, Weiss V, Collado-Vides J, Gunsalus RP, Paulsen I, Karp PD (2013) EcoCyc: fusing model organism databases with systems biology. Nucleic Acids Res 41(Database issue):D605D612. doi:10.1093/nar/gks1027

Kiviet DJ, Nghe P, Walker N, Boulineau S, Sunderlikova V, Tans SJ (2014) Stochasticity of metabolism and growth at the single-cell level. Nature 514(7522):376-379. doi:10.1038/nature13582

Lange C, Mustafi N, Frunzke J, Kennerknecht N, Wessel M, Bott M, Wendisch VF (2012) Lrp of Corynebacterium glutamicum controls expression of the brnFE operon encoding the export system for Lmethionine and branched-chain amino acids. J Biotechnol 158(4): 231-241. doi:10.1016/j.jbiotec.2011.06.003

Lee JY, Seo J, Kim ES, Lee HS, Kim P (2013) Adaptive evolution of Corynebacterium glutamicum resistant to oxidative stress and its global gene expression profiling. Biotechnol Lett 35(5):709-717. doi:10.1007/s10529-012-1135-9

Liang JC, Bloom RJ, Smolke CD (2011) Engineering biological systems with synthetic RNA molecules. Mol Cell 43(6):915-926. doi:10. 1016/j.molcel.2011.08.023

Lieder S, Jahn M, Seifert J, von Bergen M, Müller S, Takors R (2014) Subpopulation-proteomics reveal growth rate, but not cell cycling, as a major impact on protein composition in Pseudomonas putida KT2440. AMB Express 4:71. doi:10.1186/s13568-014-0071-6

Liu D, Evans T, Zhang F (2015a) Applications and advances of metabolite biosensors for metabolic engineering. Metab Eng. doi:10.1016/j. ymben.2015.06.008

Liu D, Xiao Y, Evans BS, Zhang F (2015b) Negative feedback regulation of fatty acid production based on a malonyl-CoA sensor-actuator. ACS Synth Biol 4(2):132-140. doi:10.1021/sb400158w

Long Z, Nugent E, Javer A, Cicuta P, Sclavi B, Cosentino Lagomarsino M, Dorfman KD (2013) Microfluidic chemostat for measuring single cell dynamics in bacteria. Lab Chip 13(5):947-954. doi:10.1039/ c2lc41196b
Looger LL, Dwyer MA, Smith JJ, Hellinga HW (2003) Computational design of receptor and sensor proteins with novel functions. Nature 423(6936): 185-190. doi:10.1038/nature01556

Lutz R, Bujard H (1997) Independent and tight regulation of transcriptional units in Escherichia coli via the LacR/O, the TetR/O and AraC/I1-I2 regulatory elements. Nucleic Acids Res 25(6):12031210

Mahr R, Gätgens C, Gätgens J, Polen T, Kalinowski J, Frunzke J (2015) Biosensor-driven adaptive evolution of L-valine production of Corynebacterium glutamicum. Metab Eng 32:184-194. doi:10. 1016/j.ymben.2015.09.017

Mandell DJ, Kortemme T (2009) Computer-aided design of functional protein interactions. Nat Chem Biol 5(11):797-807. doi:10.1038/ nchembio. 251

Mascher T (2013) Signaling diversity and evolution of extracytoplasmic function (ECF) sigma factors. Curr Opin Microbiol 16(2):148-155. doi:10.1016/j.mib.2013.02.001

Michener JK, Thodey K, Liang JC, Smolke CD (2012) Applications of genetically-encoded biosensors for the construction and control of biosynthetic pathways. Metab Eng 14(3):212-222. doi:10.1016/j. ymben.2011.09.004

Müller S, Harms H, Bley T (2010) Origin and analysis of microbial population heterogeneity in bioprocesses. Curr Opin Biotechnol 21(1):100-113. doi:10.1016/j.copbio.2010.01.002

Münch R, Hiller K, Barg H, Heldt D, Linz S, Wingender E, Jahn D (2003) PRODORIC: prokaryotic database of gene regulation. Nucleic Acids Res 31(1):266-269

Münch KM, Müller J, Wienecke S, Bergmann S, Heyber S, Biedendieck R, Münch R, Jahn D (2015) Polar fixation of plasmids during recombinant protein production in Bacillus megaterium results in population heterogeneity. Appl Environ Microbiol. doi:10.1128/AEM. 00807-15

Mustafi N, Grünberger A, Kohlheyer D, Bott M, Frunzke J (2012) The development and application of a single-cell biosensor for the detection of 1-methionine and branched-chain amino acids. Metab Eng 14(4):449-457. doi:10.1016/j.ymben.2012.02.002

Mustafi N, Grünberger A, Mahr R, Helfrich S, Nöh K, Blombach B, Kohlheyer D, Frunzke J (2014) Application of a genetically encoded biosensor for live cell imaging of $\mathrm{L}$-valine production in pyruvate dehydrogenase complex-deficient Corynebacterium glutamicum strains. PLoS One 9(1):e85731. doi:10.1371/journal.pone.0085731

Mustafi N, Bott M, Frunzke J (2015) Genetically-encoded biosensors for strain development and single cell analysis of Corynebacterium glutamicum. In: Burkovski A (ed) Corynebacterium glutamicum: from systems biology to biotechnological applications. Caister Academic Press, Norfolk, p 190

Newman JR, Ghaemmaghami S, Ihmels J, Breslow DK, Noble M, DeRisi JL, Weissman JS (2006) Single-cell proteomic analysis of $S$. cerevisiae reveals the architecture of biological noise. Nature 441(7095):840-846. doi:10.1038/nature04785

$\mathrm{Ng} \mathrm{CY,} \mathrm{Khodayari} \mathrm{A,} \mathrm{Chowdhury} \mathrm{A,} \mathrm{Maranas} \mathrm{CD} \mathrm{(2015)} \mathrm{Advances} \mathrm{in} \mathrm{de}$ novo strain design using integrated systems and synthetic biology tools. Curr Opin Chem Biol 28:105-114. doi:10.1016/j.cbpa.2015. 06.026

Novichkov PS, Kazakov AE, Ravcheev DA, Leyn SA, Kovaleva GY, Sutormin RA, Kazanov MD, Riehl W, Arkin AP, Dubchak I, Rodionov DA (2013) RegPrecise 3.0-a resource for genomescale exploration of transcriptional regulation in bacteria. BMC Genomics 14:745. doi:10.1186/1471-2164-14-745

Ohlendorf R, Vidavski RR, Eldar A, Moffat K, Möglich A (2012) From dusk till dawn: one-plasmid systems for light-regulated gene expression. J Mol Biol 416(4):534-542. doi:10.1016/j.jmb.2012.01.001

Oide S, Gunji W, Moteki Y, Yamamoto S, Suda M, Jojima T, Yukawa H, Inui M (2015) Thermal and solvent stress cross-tolerance conferred to Corynebacterium glutamicum by adaptive laboratory evolution. 
Appl Environ Microbiol 81(7):2284-2298. doi:10.1128/AEM. 03973-14

Podgornaia AI, Laub MT (2013) Determinants of specificity in twocomponent signal transduction. Curr Opin Microbiol 16(2):156162. doi:10.1016/j.mib.2013.01.004

Raman S, Rogers JK, Taylor ND, Church GM (2014) Evolution-guided optimization of biosynthetic pathways. Proc Natl Acad Sci U S A 111(50):17803-17808. doi:10.1073/pnas.1409523111

Reyes LH, Gomez JM, Kao KC (2014) Improving carotenoids production in yeast via adaptive laboratory evolution. Metab Eng 21:2633. doi:10.1016/j.ymben.2013.11.002

Rhodius VA, Segall-Shapiro TH, Sharon BD, Ghodasara A, Orlova E, Tabakh H, Burkhardt DH, Clancy K, Peterson TC, Gross CA, Voigt CA (2013) Design of orthogonal genetic switches based on a crosstalk map of sigmas, anti-sigmas, and promoters. Mol Syst Biol 9:702. doi:10.1038/msb.2013.58

Salgado H, Gama-Castro S, Peralta-Gil M, Diaz-Peredo E, SanchezSolano F, Santos-Zavaleta A, Martinez-Flores I, Jimenez-Jacinto V, Bonavides-Martinez C, Segura-Salazar J, Martinez-Antonio A, Collado-Vides J (2006) RegulonDB (version 5.0): Escherichia coli $\mathrm{K}-12$ transcriptional regulatory network, operon organization, and growth conditions. Nucleic Acids Res 34(Database issue):D394 D397. doi:10.1093/nar/gkj156

Schallmey M, Frunzke J, Eggeling L, Marienhagen J (2014) Looking for the pick of the bunch: high-throughput screening of producing microorganisms with biosensors. Curr Opin Biotechnol 26:148-154. doi:10.1016/j.copbio.2014.01.005

Schendzielorz G, Dippong M, Grünberger A, Kohlheyer D, Yoshida A, Binder S, Nishiyama C, Nishiyama M, Bott M, Eggeling L (2014) Taking control over control: use of product sensing in single cells to remove flux control at key enzymes in biosynthesis pathways. ACS Synth Biol 3(1):21-29. doi:10.1021/sb400059y

Siedler S, Schendzielorz G, Binder S, Eggeling L, Bringer S, Bott M (2014a) SoxR as a single-cell biosensor for NADPH-consuming enzymes in Escherichia coli. ACS Synth Biol 3(1):41-47. doi:10. 1021/sb400110j

Siedler S, Stahlhut SG, Malla S, Maury J, Neves AR (2014b) Novel biosensors based on flavonoid-responsive transcriptional regulators introduced into Escherichia coli. Metab Eng 21:2-8. doi:10.1016/j. ymben.2013.10.011

Silva-Rocha R, de Lorenzo V (2012) Broadening the signal specificity of prokaryotic promoters by modifying cis-regulatory elements associated with a single transcription factor. Mol BioSyst 8(7):1950-1957. doi: $10.1039 / \mathrm{c} 2 \mathrm{mb} 25030 \mathrm{f}$

Stanton BC, Siciliano V, Ghodasara A, Wroblewska L, Clancy K, Trefzer AC, Chesnut JD, Weiss R, Voigt CA (2014) Systematic transfer of prokaryotic sensors and circuits to mammalian cells. ACS Synth Biol 3(12):880-891. doi:10.1021/sb5002856

Tang SY, Cirino PC (2011) Design and application of a mevalonateresponsive regulatory protein. Angew Chem Int Ed 50(5):1084 1086. doi:10.1002/anie.201006083

Tang SY, Fazelinia H, Cirino PC (2008) AraC regulatory protein mutants with altered effector specificity. J Am Chem Soc 130(15):52675271. doi:10.1021/ja7109053

Tang SY, Qian S, Akinterinwa O, Frei CS, Gredell JA, Cirino PC (2013) Screening for enhanced triacetic acid lactone production by recombinant Escherichia coli expressing a designed triacetic acid lactone reporter. J Am Chem Soc 135(27):10099-10103. doi:10.1021/ ja402654z

Tracy BP, Gaida SM, Papoutsakis ET (2008) Development and application of flow-cytometric techniques for analyzing and sorting endospore-forming clostridia. Appl Environ Microbiol 74(24): 7497-7506. doi:10.1128/AEM.01626-08

Uchiyama T, Miyazaki K (2010a) Product-induced gene expression, a product-responsive reporter assay used to screen metagenomic libraries for enzyme-encoding genes. Appl Environ Microbiol 76(21):7029-7035. doi:10.1128/AEM.00464-10

Uchiyama T, Miyazaki K (2010b) Substrate-induced gene expression screening: a method for high-throughput screening of metagenome libraries. Methods Mol Biol 668:153-168. doi:10.1007/978-160761-823-2_10

Uchiyama T, Watanabe K (2008) Substrate-induced gene expression (SIGEX) screening of metagenome libraries. Nat Protoc 3(7): 1202-1212. doi:10.1038/nprot.2008.96

Umeyama T, Okada S, Ito T (2013) Synthetic gene circuit-mediated monitoring of endogenous metabolites: identification of GAL11 as a novel multicopy enhancer of s-adenosylmethionine level in yeast. ACS Synth Biol 2(8):425-430. doi:10.1021/sb300115n

van der Meer JR, Belkin S (2010) Where microbiology meets microengineering: design and applications of reporter bacteria. Nat Rev Microbiol 8(7):511-522. doi:10.1038/nrmicro2392

van Sint Fiet S, van Beilen JB, Witholt B (2006) Selection of biocatalysts for chemical synthesis. Proc Natl Acad Sci U S A 103(6):16931698. doi:10.1073/pnas.0504733102

Vasdekis AE, Stephanopoulos G (2015) Review of methods to probe single cell metabolism and bioenergetics. Metab Eng 27:115-135. doi:10.1016/j.ymben.2014.09.007

Wang P, Robert L, Pelletier J, Dang WL, Taddei F, Wright A, Jun S (2010) Robust growth of Escherichia coli. Curr Biol 20(12):1099 1103. doi:10.1016/j.cub.2010.04.045

Want A, Thomas OR, Kara B, Liddell J, Hewitt CJ (2009) Studies related to antibody fragment (Fab) production in Escherichia coli W3110 fed-batch fermentation processes using multiparameter flow cytometry. Cytometry A 75(2):148-154. doi:10.1002/cyto.a.20683

Wendisch VF (2014) Microbial production of amino acids and derived chemicals: synthetic biology approaches to strain development. Curr Opin Biotechnol 30:51-58. doi:10.1016/j.copbio.2014.05.004

Wiechert W, Noack S (2011) Mechanistic pathway modeling for industrial biotechnology: challenging but worthwhile. Curr Opin Biotechnol 22(5):604-610. doi:10.1016/j.copbio.2011.01.001

Wilson D, Charoensawan V, Kummerfeld SK, Teichmann SA (2008) DBD-taxonomically broad transcription factor predictions: new content and functionality. Nucleic Acids Res 36(Database issue): D88-D92. doi:10.1093/nar/gkm964

Wise AA, Kuske CR (2000) Generation of novel bacterial regulatory proteins that detect priority pollutant phenols. Appl Environ Microbiol 66(1):163-169

Xie W, Lv X, Ye L, Zhou P, Yu H (2015) Construction of lycopeneoverproducing Saccharomyces cerevisiae by combining directed evolution and metabolic engineering. Metab Eng 30:69-78. doi: 10.1016/j.ymben.2015.04.009

Xu P, Li L, Zhang F, Stephanopoulos G, Koffas M (2014a) Improving fatty acids production by engineering dynamic pathway regulation and metabolic control. Proc Natl Acad Sci U S A 111(31):1129911304. doi:10.1073/pnas.1406401111

Xu P, Wang W, Li L, Bhan N, Zhang F, Koffas MA (2014b) Design and kinetic analysis of a hybrid promoter-regulator system for malonylCoA sensing in Escherichia coli. ACS Chem Biol 9(2):451-458. doi:10.1021/cb400623m

Yang J, Seo SW, Jang S, Shin SI, Lim CH, Roh TY, Jung GY (2013) Synthetic RNA devices to expedite the evolution of metaboliteproducing microbes. Nat Commun 4:1413. doi:10.1038/ ncomms 2404

Zhang F, Carothers JM, Keasling JD (2012) Design of a dynamic sensorregulator system for production of chemicals and fuels derived from fatty acids. Nat Biotechnol 30(4):354-359. doi:10.1038/nbt.2149

Zhang J, Jensen MK, Keasling JD (2015) Development of biosensors and their application in metabolic engineering. Curr Opin Chem Biol 28: 1-8. doi:10.1016/j.cbpa.2015.05.013 